the potential value of an open access service is unfounded, and we believe that this service should become more widely available.

1 Fisher JA, Surridge JG, Vartan CP, Lochry CA. Upper gastrointestinal endoscopy-a GP' service. Br. Med Y 1977;ii:1199-201.

2 Mann J, Holdstock (G, Harman M, Machin D), Lochry CA. Scoring sistem to improve cost effectiveness of open access endoscopy. Br. Med J 1983;287 $937-40$
3 Holdstock G, Harman M, Machin D, Parel C, Llowd RS, Prospective testing of a coring system designed to improve case selection for upper gastrointestinal

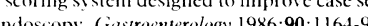

+ Mead GM, Harris A, Webster (iK, Langman MJS. Uses of barium meal examination in despeptic patients under 50 years. Br.Med 7 1977;ii: 1460-1.

Mathers N. Hodgkin P. The Gatekeeper and the Wizard: a fairy tale. Br Med $1989 ; 298: 172-4$

6 Gear MWL, Wilkinson SP. Open-access upper alimentary endoscopy. Br $\mathcal{F}$ Hosp Med 1989;41:438-4t

\title{
Cervical cytology in the Vale of Trent faculty of the Royal College of General Practitioners, 1985-8
}

\author{
Andrew Wilson
}

\begin{abstract}
Objective-To assess changes in the organisation and performance of cervical cytology programmes in the practices of members of the Vale of Trent faculty of the Royal College of General Practitioners.

Design-Retrospective audits completed in 1985 and 1988 by general practitioners on a sequential sample of 100 records of women aged 35-64 in their practice.
\end{abstract}

Setting-General practices in which one or more partners were members or associates of the Vale of Trent faculty of the college, of which 76 participated in the first audit and 55 (82\% of 67 eligible practices) in the second.

Subjects-Sequential samples of 100 women born between 1 January 1920 and 31 December 1949 (first audit) and between 1 January 1923 and 31 December 1952 (second audit) whose surnames began with $P$ or $B$ respectively.

Main outcome measures-Percentage of women in each practice with a record of cervical cytology performed in the previous five years and percentage with no recorded smear.

Results - Of the 76 practices completing the audit in $1985,55(82 \%$ of those eligible) repeated the exercise in 1988. Performance was not significantly different in practices that did and did not respond. The median percentage of women who had had a smear in the previous five years was $49 \%$ and $69 \%$ in 1985 and 1988 respectively $(p<0.001)$ and that of women with no record of a cervical smear was $28 \%$ and $16 \%$ respectively $(p<0 \cdot 001)$. All but six practices showed improvement in both outcome measures. In both audits an active call system was associated with a significantly increased performance $(p<0 \cdot 05)$. In nine practices $(16 \%) 80 \%$ or more of the samples of women had had a smear in the previous five years.

Conclusion-Organisation and performance of practices audited improved between 1985 and 1988 . Although this might result from participation in the first audit, it probably represents a more general trend within primary care.

Action-Between the two audits more practices $(87 \% v 67 \%)$ had developed a policy on screening, and this was more likely to include the aim of performing regular smears on all sexually active women $(98 \% v 80 \%)$.

Department of General Practice, University of Nottingham, Queen's Medical Centre,

Nottingham NG7 2UH Andrew Wilson, MRCGP, lecturer

$\operatorname{Br} \operatorname{Med} \mathcal{F} 1990 ; 300: 376-\varnothing$
2004 women in England and Wales in 1986, 1 most of which might have been prevented by achieving high rates of coverage in a coordinated cervical cytology programme.' Participation by general practitioners is an essential feature of any such programme, but a recent national survey showed that only $43 \%$ of general practitioners operated a screening system that could identify and call previously untested women. ${ }^{3}$ The rate of coverage of a programme is the crucial determinant of its success, ${ }^{+}$although these rates are difficult to determine as routinely published data on cytology are presented as numbers of smears rather than number of women. The government has recently proposed a target of $80 \%$ coverage for women who have had a smear within the previous five years, excluding those who have had a hysterectomy. ${ }^{\circ}$ Participation in peer group audit improves general practitioners performance, at least for those directly involved. "7 The Royal College of General Practitioners has proposed peer group audit as a major route to higher standards, and local faculties have been encouraged to stimulate such activity.

I describe one initiative in which members of the college were invited to audit the organisation and performance of their cervical cytology programmes. The audit was repeated three years later. The aim of these audits was to detect any features of the programmes associated with high performance and to report changes over the three years.

\section{Subjects and methods}

In spring of 1985 members of the Vale of Trent faculty of the Royal College of General Practitioners were invited to take part in an audit of cervical cytology." They were asked about their policy on cervical smears and requested to audit their performance by drawing a sequential sample of 100 women born between 1 January 1920 and 31 December 1949 from their records, starting with records filed under the letter P. Practices in which more than one doctor received the questionnaire were asked to submit only one audit. The audit was performed in 76 practices, representing 101 members $(42 \%$ response rate). The performance measures were the number of women in the sample who had no record of a smear and the number who had had a smear in the previous five years. Respondents were sent their own results, aggregate results of the audit, and their order of rank.

In spring 1988 a second audit was planned. Of the 76 doctors who had performed the first audit, 69 were thought still to be in post and were invited to repeat their audit, using an identical method, but this time selecting 100 women born between 1 January 1923 and 31 December 1952, starting from the letter B in their records. After the initial posting it was realised that one doctor had moved and another had retired, reducing the denominator to 67 practices. The results of the second audit were compared with those of the first with non-parametric tests. 


\section{Results}

In the first audit the median percentage of women having a smear within the previous five years was $49 \%$ and that of women who had no record of a smear was $27 \%$. Of all the variables measured, only the presence of an active call system was associated with improved performance. One practice achieved the target of $80 \%$ of women having a smear within five years.

Fifty five practices $(82 \%)$ completed the second audit. Responders and non-responders compared in the first audit showed no significant difference in performance. Table I shows the policy changes in these practices over the three year peiod. Practices were more likely to aim at taking smears from all sexually active women, to increase the freqency of targeting younger women, and to take a repeat smear one year after a first normal smear. The number of practices performing the last routine smear at age 65 increased. Whether or not the women were taking the pill was less likely to influence the frequency of smears. More practices $(87 \% v 69 \%)$ had established a policy for cervical cytology, and the number of practices in which most smears were peformed by the practice nurse increased, from $24 \%$ to $36 \%$. Table II shows the changes in call and recall systems over the same period. The number of practices using practice based systems increased, and the number using computers increased more than threefold. Table III shows the differences in performance between the two audits. With both outcome measures performance was significantly increased, the median percentage of women with no record of a smear decreasing by $11 \%$ and that of women having a smear within five years increasing by a fifth. All but six practices showed an increased performance with both measures. Nine practices $(16 \%)$ reached a $80 \%$ coverage or more for the sample who had had a smear within the previous five years.

Previous studies have suggested that about $6 \%$ of women are ineligible for a cytology programme because of hysterectomy. ${ }^{10}$ Assuming that in this study such women did not have a smear unnecessarily, the adjusted median percentage coverage over five years was $100 / 94$ 1.06 times higher than that reported-that is, $73 \%$ at

TABLE I-Changes in practice and policy towards cervical cytology in 55 practices in Vale of Trent faculty, 1985-8. Figures are numbers (percentages)

First audit (1985) Second audit (1988)

\begin{tabular}{|c|c|c|}
\hline \multicolumn{3}{|c|}{$\begin{array}{l}\text { Frequency of smear for women aged } \\
\text { Three yearly } \\
\text { Five yearly }\end{array}$} \\
\hline \multirow{2}{*}{\multicolumn{3}{|c|}{$\begin{array}{l}\text { Frequency of smear in women aged } 46 \\
\text { Three yearly } \\
\text { Five yearly }\end{array}$}} \\
\hline & & \\
\hline \multirow{6}{*}{\multicolumn{3}{|c|}{$\begin{array}{l}\text { Aim at repeating first normal smear a } \\
\text { Age last smear taken (years): } \\
60 \\
65 \\
70 \\
\text { Death } \\
\text { Practice policy established for cervic } \\
\text { Practice nurse performs most smears }\end{array}$}} \\
\hline & & \\
\hline & & \\
\hline & & \\
\hline & & \\
\hline & & \\
\hline \multicolumn{3}{|c|}{$\begin{array}{l}\text { TABLE II-Changes in call and } \\
\text { recall systems in } 55 \text { practices in } \\
\text { Vale of Trent faculty, } 1985-8 . \\
\text { Figures are numbers } \\
\text { (percentages) }\end{array}$} \\
\hline & $\begin{array}{l}\text { First } \\
\text { audit }\end{array}$ & $\begin{array}{l}\text { Second } \\
\text { audit }\end{array}$ \\
\hline \multicolumn{3}{|c|}{ Call system } \\
\hline Manual only & $24(44)$ & $20(36)$ \\
\hline Computer & $2(4)$ & $10(18)$ \\
\hline None & $29(53)$ & $25(45)$ \\
\hline \multicolumn{3}{|c|}{ Recall system } \\
\hline Manual only & $38(69)$ & $33(60)$ \\
\hline Computer & $4(7)$ & $13(24)$ \\
\hline None & $13(24)$ & $9(16)$ \\
\hline
\end{tabular}

$\begin{array}{rr}17(31) & 35(64) \\ 35(64) & 18(33) \\ 8(15) & 13(25) \\ 43(78) & 40(73) \\ 25(45) & 35(64) \\ 12(22) & 6(11) \\ 25(45) & 41(75) \\ 11(20) & 6(11) \\ 6(11) & 1(2) \\ 38(69) & 48(78) \\ 13(24) & 20(36)\end{array}$

the second audit. Adjusting the $80 \%$ target using this assumption results in a revised target of $80 / 1 \cdot 06,75 \%$ of a population, including women who have had a hysteretomy; in the second audit 16 practices (29\%) achieved this target. The lower target suggested by the government is half of eligible women, which, by the above calculation, is equivalent to about $47 \%$ of the total age group; in the second audit 53 practices (96\%) achieved this.

The results of the second audit were analysed to elucidate any association between organisation and performance. Practices in which most smears were taken by a practice nurse and those in which most were performed by the doctor were not significantly dif-
TABLE III-Changes in coverage of cervical cytologv in 55 practices between 1985 and 1988

\begin{tabular}{lcc}
\hline & \multicolumn{2}{c}{ Outcome measure } \\
\cline { 2 - 3 } & $\begin{array}{c}\text { No record of } \\
\text { smear }\end{array}$ & $\begin{array}{c}\text { Smear within } \\
\text { past five years }\end{array}$ \\
\hline Median (range) percentage in each practice: & & \\
$\quad$ First audit (1985) & $28(6-47)$ & $49(27-80)$ \\
Second audit (1988) & $16(0-35)$ & $69(37-99$ \\
No(\%) of practices: & $49(89)^{\star}$ & $52(95)^{\star}$ \\
With improved performance & $4(7)$ & 3 \\
With reduced performance & $2(4)$ & 0 \\
With no change in performance &
\end{tabular}

${ }^{\star} \mathrm{p}=<0.001$ (Wilcoxon's matched pairs signed ranks test).

TABLE IV-Performance of 55 practices according to presence of call or recall system (median percentage values)

\begin{tabular}{lcc}
\hline & \multicolumn{2}{c}{ Outcome measure } \\
\cline { 2 - 3 } & $\begin{array}{c}\text { No record of } \\
\text { smear }\end{array}$ & $\begin{array}{c}\text { Smear within past } \\
\text { five years }\end{array}$ \\
\hline Call system $(n=30)$ & $14 \cdot 0$ & $70 \cdot 5$ \\
No call system $(n=25)$ & $17 \cdot 0$ & $62 \cdot 0^{\star}$ \\
Recall system $(n=46)$ & $14 \cdot 5$ & $69 \cdot 0$ \\
No recall system $(n=9)$ & $17 \cdot 0$ & $62 \cdot 0$ \\
\hline
\end{tabular}

${ }^{\star} \mathrm{p}=<0 \cdot 05$ (Mann-Whitney U test).

ferent. As in the first audit only the presence of a call system was associated with increased coverage (table IV).

\section{Discussion}

This study shows a willingness among members of the college to take part in audit. It is encouraging that the $82 \%$ response to the second audit was not related to performance in the first. There is a danger in giving too much weight to results from individual practices, especially their order of rank as with such small numbers sampling error is high. For example, the $95 \%$ confidence interval of a result of 57 out of 100 women having had a smear within five years is $47-67 \%$. In the second audit the rank for these would be 53rd and 31 st respectively. In aggregate, however, the study disclosed substantial changes in organisation and peformance between 1985 and 1988. In the second audit there was more agreement among practices, and this consensus was close to the policy of the district health authority. The results showed a pronounced improvement in performance, although without a control group of practices it is impossible to say whether this was a result of taking part in the first audit or reflection of more widespread changes in general practice. The limited impact of audit on general practitioners not directly participating in organising audit ${ }^{7}$ suggests that changes in general practice are the more likely explanation.

In this audit one aim was to maximise participation by making the task simple. This entailed some compromise of scientfic rigour, particularly in chosing a small non-random sample from each practice. Information was not sought on women ineligible for smears or women declining the offer, proportions that might vary among practices. Although these considerations would be vital if performance was being measured for contractual reasons, they do not detract from the educational aim of the exercise, which was to stimulate interest and activity in cervical screening and to encourage practices to look at their own performance in more detail. It is highly implausible that the improved performance in the second audit resulted from bias owing to the alphabetical source of the sample.

Although the practices taking part are almost certainly not representative of cervical cytology screening 
locally or nationally, the finding that within the sample a call system was associated with improved performance replicates other studies, which found that unstructured case finding failed to produce high rates. ${ }^{112}$ Because of the issues of method discussed earlier the estimate of practices reaching the target of $80 \%$ coverage $(28 \%)$ is crude. However, this result from highly motivated practices suggests that to be effective the target will have to be seen as an inducement to higher performance rather than a reward for achieving it. Further studies on representative practices are needed to predict whether the target will act as a positive or negative incentive.

In future, outside agencies will provide general practitioners with data about their performance, including that on rates of cervical cytology. Such unsolicited feedback has not proved to be effective in changing behaviour, ${ }^{13}$ although it may be necessary in terms of accountability or for contractual reasons ${ }^{14}$; there will remain a place for the type of voluntary, locally organised exercise described here.

This study would not have been possible without the cooperation and help of Janet Baily, administrative secretary for the Vale of Trent faculty.
1 Office of Population Censuses and Surveys. Mortality statistics. Review of the registrar general on deaths by cause, sex and age in England and Wales. London: HMSO, 1986

2 Intercollegiate Working Party on Cervical Cytology Screening. Report. Potters Bar, Hertfordshire: Progress Press, 1987

3 Havelock C, Edwards R, Cuzik J, Chamberlain J. The organisation of cervical cytology screening in general practice. $\mathcal{F} R$ Coll Gen Pract 1988;38:207-11.

4 Smith A, Elkind A, Eardley A. Making cervical screening work. Br Med $\mathcal{F}$ 1989;298:1662-4.

5 Health Departments of Great Britain. General practice in the National Health Service. The 1990 contract. London: HMSO, 1989.

6 Grol R, Mikkink H, Schelleris F. The effects of peer review in general practice. $\mathcal{F} R$ Coll Gen Pract 1988;38:10-3.

7 Anderson CA, Chambers C, Clamp M, et al. Can audit improve patient care? Effects of studying use of digoxin in general practice. Br Med $\mathcal{J} 1988 ; 297$ : Effects

8 Royal College of General Practitioners. The front line of the health service. London: RCGP, 1987. (Report from general practice 25.

9 Wilson AD. Cervical cytology: a general practice audit. Fumily Practice 1987;4:56-60

10 Ross SK. Cervical cytology screening and government policy. Br Med $\mathcal{f}$ 1989;299:101-4

11 Pierce M, Lundy S, Palinsamy A, Winning S, King J. Prospective randomised controlled trial of methods of call and recall for cervical cytology screening. $B$ Med f 1989;299:160-2.

12 Fleming DM, Lawrence MSTA, Cross KW. List size, screening methods and other characteristics of practices in relation to preventive care. $\mathrm{Br} \mathrm{Med}$ 1985;291:869-72.

13 Horder J, Bosanquet N, Stocking B. Ways of influencing the behaviour of general practitioners. $\mathcal{F} R$ Coll Gen Pract 1986;36:517-21.

14 Buckley EG. Quality assessment or quality control? f $R$ Coll Gen Pract 1989;39:309-12.

(Accepted 29 November 1989)
Richard Baker

\section{Introduction}

The purpose of medical audit is to improve the quality of care. If badly executed or used for any other purpose audit may waste time and resources that should be used in caring for patients. Whatever we may think of the other proposals in the white paper ${ }^{1}$ the new arrangements for audit in general practice offer the profession an opportunity to introduce effective audit that will substantially improve the quality of care. The difficulty is to ensure that audit in practices or organised by medical audit advisory groups is effective in improving care and not wasteful of resources or demoralising to the participants. Audit should therefore be subjected to the same degree of critical evaluation as any other innovations in medicine, such as new treatments or forms of investigation; it has the same potential as these more traditional medical activities to cause harm as well as benefit. I will draw on the experience of some of the successful and unsuccessful audits carried out in my own practice to show why some audits lead to improvements in care and others do not.

General Practice Unit,

\section{Department of}

Epidemiology and

Community Medicine, University of Bristol, Bristol BS8 2PR

Richard Baker, MRCGP, research fellow

Correspondence to: Leckhampton Surgery, 17 Moorend Park Road, Leckhampton, Cheltenham, Gloucestershire GL53 0LA

\section{Problem solving with audit}

The most common reason for failure of audit to improve the quality of care is that the findings do not cause changes in day to day clinical practice. Deficiencies are ignored, either because they are seen as unimportant or because the changes required seem so considerable as to be impracticable. Using audit to solve problems is one way to avoid this difficulty; it is undertaken only when a problem is suspected, which the practice wishes to correct. If audit is to be effective the participants should be the practice team or some of its members-it is the practice that has the problem, and its members are usually the only people who can put it right.

Problems in providing care may be identified in various ways. There cannot be many general practitioners who are not aware of most of the strengths and weaknesses of the practices in which they work. For example, patients may complain about how difficult it is to speak to their doctor on the telephone or to arrange for repeat prescriptions. The receptionists or practice nurses may more often be the recipients of this type of complaint than the doctors themselves. There are other ways to spot problems. A potentially avoidable important event such as the late diagnosis of appendicitis may indicate a problem of practice management or medical skill that needs investigating; the information from prescribing analysis and cost data may show excessive prescribing of antibiotics; or a training practice inspection may disclose disorganised records. If the practice examines the evidence from such sources and concludes that a problem exists then audit provides one solution. Some types of audit can disclose deficiencies in care, but categorising those deficiencies as problems and then dealing with them demands a different approach. Problems can be thought of as deficiencies that those in the practice think are so important that corrective action must be taken. Some examples may help explain the difference.

\section{Successful audits}

Audit 1-The problem: doctors and staff reported to the practice meeting that patients complained how long they had to wait for routine appointments (urgent appointments are available on the same day). At the first data collection the receptionists kept a record of the waiting interval in days regularly over three months. The average wait for an appointment with the patient's chosen doctor was $3 \cdot 7$ days. The solution: we agreed to aim at around three days as a target and introduced a new system offering more and longer appointments. At the second data collection the 